\title{
Estímulos a la investigación científica de la UNAH: Un mecanismo de promoción y desarrollo de la actividad investigativa
}

\begin{abstract}
CIENCIA Y TECNOLOGÍA (CT) Entrevista al Profesor Miguel Barahona, catedrático en la Facultad de Humanidades y Artes en la Escuela de Letras, posee una licenciatura en Letras en la Facultad de Humanidades y Arte, y Máster en Filología Hispánica. Actualmente imparte las cátedras de Español, Redacción General, Semiótica y Técnicas de la Lectura.
\end{abstract}

CT/ ¿Que representa para un investigador de su trayectoria los premios a la Investigación Científica?

MB/ En lo personal, el premio de Investigación Científica representa un incentivo en el presupuesto de que la ciencia y el conocimiento son los aspectos mas representativos de nuestra Universidad Nacional. De esta forma, lograr una mención o un premio específico, se vuelve un activo primordial en el logro curricular, para cada uno de los docentes. Así obtener un premio muy reconocido, renueva y mantiene el espíritu investigativo.

El premio de investigación, también recompensa nuestra labor en la enseñanza universitaria y además representa un logro de matices individuales y colectivos, que sirve de ejemplo para incentivar a otras personas a buscar y seguir el camino investigativo.

CT/ ¿Cómo motiva a los investigadores de la UNAH este tipo de incentivos a la Investigación Científica?

MB/ A seguir en el ámbito investigativo, pero lo más importante; incentivar a nuestros colegas y alumnos para que conformen grupos de trabajo y así realicen investigaciones interdisciplinarias.

$\mathrm{CT} /$ ¿Como se relacionan los componentes de Investigación, Docencia y Vinculación y como inciden en ellos los premios de Investigación?

MB/ Son elementos estrechamente asociados, puesto que incita a nosotros los 
docentes a realizar la diaria práctica educativa focalizándola en una tarea crítica hacia la formación. Los tres elementos perceptibles representan la institucionalidad ante la sociedad, además demuestra que la UNAH los está ya generando a través de esta triada reflejándola por medio del rol participativo con la finalidad de lograr el desarrollo integral de nuestra Nación. Así nuestra Institución logra demostrar que la inversión que hace la Republica de Honduras al apostarle a la educación pública superior, ya tiene una meta palpable y sobretodo que la misma produce frutos. La incidencia de los componentes de Investigación, Docencia y Vinculación en los premios de investigación, se da en el logro curricular de los investigadores, puesto que la experiencia investigativa universitaria, solo se puede lograr si se unifica en forma estructural, con la docencia y la vinculación.

\section{CT/ ¿Como han ido evolucionando los premios de Investigación Científica, desde su creación hasta la actualidad?}

MB/ Según entiendo, hace algunos años los premios de investigación se otorgaban a docentes de un alto perfil, y las categorías eran muy reducidas. En la actualidad la Dirección de Investigación Científica modifica la estructura de la convocatoria, y así de esta manera, amplia todas las categorías de los investigadores docentes y además promueve la creación de categorías que integren los estudiantes, que de hecho constituyen los nuevos investigadores en formación.

\section{CT/ ¿Cómo valora la ampliación y creación de las nuevas categorías de los premios de Investigación Científica?}

MB/ Muy importante. Este abanico categórico ampliado, genera y promueve una de las mayores participaciones para optar a los premios. Esto hace que la convocatoria se vuelva en la actualidad mas democrática, puesto que incentiva a todos las Escuelas y Facultades de la UNAH a nivel nacional a presentar anualmente candidaturas de sus investigadores en todas las categorías. Así se genera una mayor participación para optar a los premios, pero lo interesante de esta ampliación en las categorías de los premios, se basa en otra clase de incentivo, el de la popularización y la referencia para cada uno de los investigadores universitarios que logran obtener.

\section{CT/ ¿Cómo cataloga los criterios con los cuales son evaluados los investigadores que optan a los premios de Investigación Científica?}

MB/ Los criterios de evaluación muestran una gran asertividad, puesto que dividen dichos criterios en aspectos evaluativos puntuales de cada una de las experiencias 


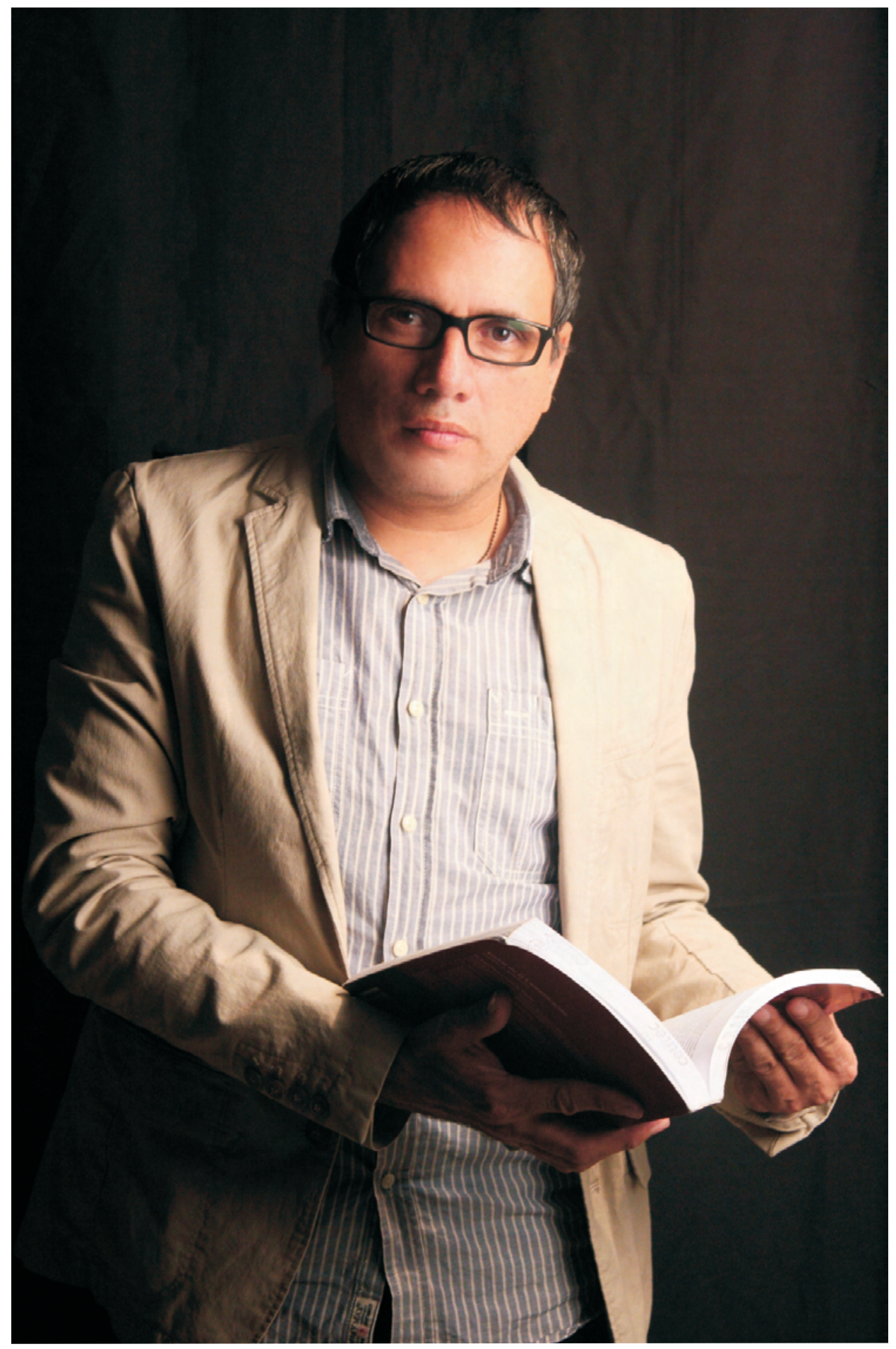


de los investigadores. Los pesos de medición que tienen cada punto de la evaluación, van conforme a los lineamientos en cada una de las categorías propuestas para las candidaturas.

CT/ ¿Cómo valora la amplitud que le da la UNAH a la invitación para los premios de Investigación Científica?

MB/ En un alto grado, puesto que ahora, con esta ampliación de categorías, cada uno de los investigadores, pueden optar a una candidatura especifica, y además se visualizan las altas posibilidades de lograr obtener el premio.

\section{CT/ ¿Cómo valora la creación de los premios de Investigación Científica para la categoría de estudiantes?}

MB/ Esta categoría incentiva a la búsqueda y formación de nuevos investigadores, quienes de hecho, son el relevo natural y generacional de los actuales investigadores. En lo personal, creo que ha sido muy acertada la creación institucional de esta nueva categoría, puesto que pone de manifiesto como la Dirección de Investigación Científica, conoce de la necesidad de formar a estos nuevos investigadores, y esta cantera la constituye la actual población estudiantil universitaria.

\section{CT/ ¿Qué incidencia cree Ud. que tendrá en los estudiantes, en su formación como futuros investigadores los premios de Investigación Científica?}

MB/ La visibilidad para los nuevos investigadores, esto los hace posicionarse dentro de una realidad y una visión investigativa interdisciplinaria y además dan pie a vitalizar la perspectiva del campo de investigación de nuestraAlma Mater 